\title{
Treating the elderly patient with acute myelogenous leukemia
}

\author{
Mehrdad Payandeh, Mehrnoush Aeinfar \\ Department of Hematology-Oncology, Kermanshah University of Medical Science (KUMS), Kermanshah, I ran \\ Correspondence: Mehrdad Payandeh. Address: Department of Hematology-Oncology, Kermanshah University of \\ Medical Science (KUMS), Kermanshah, Iran. E-mail: md.payandeh@yahoo.com
}

Received: J une 13, 2012

DOI : $10.5430 / j h m . v 2 n 4 p 22$

Accepted: July 23, 2012

Online Published: November 19, 2012

\section{Abstract}

Among patients with acute myeloid leukemia (AML), treatment regimens and outcomes may differ among younger and older adults. Although there is no clear dividing line when considering age in AML, in most studies, "older adults" was defined as over age 60.The management of older patients with AML is a difficult challenge. Older adults are more likely to have comorbidities that can limit treatment options; the disease tends to be more aggressive biologically; and outcomes are worse than in younger patients. Decisions regarding the optimal treatment of acute myelogenous leukemia in the elderly patient require the consideration of multiple factors. Population-based studies have demonstrated that, for all age groups, aggressive therapy results in improved survival and quality of life when compared with palliative care. The optimal induction and post remission regimen for older patients has yet to be determined. Furthermore, not all patients are candidates for such therapy. Consideration of patient and disease-related factors can help to determine the appropriateness of intensive therapy in a given patient. For those patients, for whom aggressive induction therapy does not seem to be in their best interest, novel agents are being investigated that will hopefully address the issues of induction death and early relapse associated with these patient populations. This topic review will discuss the treatment of older adults with AML.

\section{Key words}

Acute myeloid leukemia, Hematopoietic cell transplantation, Complete remission, High dose cytarabine, Eastern Cooperative Oncology Group

\section{I ntroduction}

Among patients with acute myeloid leukemia (AML), treatment regimens and outcomes may differ among younger and older adults. Although there is no clear dividing line when considering age in AML, in most studies, "older adults" was defined as over age 60.The management of older patients with AML is a difficult challenge ${ }^{[1]}$.

Older adults are more likely to have comorbidities that can limit treatment options; disease tends to be more aggressive biologically; and outcomes are worse than in younger patients.

Decisions regarding the optimal treatment of acute myelogenous leukemia in the elderly patient require the consideration of multiple factors. Population-based studies have demonstrated that, for all age groups, aggressive therapy results in 
improved survival and quality of life when compared with palliative care. The optimal induction and post remission regimen for older patients has yet to be determined.

Furthermore, not all patients are candidates for such therapy. Consideration of patient and disease-related factors can help to determine the appropriateness of intensive therapy in a given patient. For those patients for whom aggressive induction therapy does not seem to be in their best interest, novel agents are being investigated that will hopefully address the issues of induction death and early relapse associated with these patient populations.

This topic review will discuss the treatment of older adults with AML.

\section{Most questions that must be answered}

I. How is acute myeloid leukemia in the elderly different?

II. What is the standard therapy for the older patient with AML?

III. Who should not receive intensive therapy?

IV. What treatment options are available for patients who are not candidates for intensive induction therapy?

Acute myeloid leukemia presents at all ages, but is mainly a disease of the elderly, with a median age of 69 years in the white US population ${ }^{[2]}$. In the Swedish Acute Leukemia Registry, 68\% of patients diagnosed with AML since 1973 were over age 60 years; between 1997 and 2005, 75\% was aged 60 years or more ${ }^{[3]}$.

Prognosis worsens every decade beginning at age 30 to $40{ }^{[4]}$. A report by the German Acute Myeloid Leukemia Cooperative Group looked at patients 16 to 85 years of age enrolled in two consecutive trials in 1992 and 1999 with no upper age limit who had AML ${ }^{[5]}$. In a multivariate analysis of prognostic factors, age > 60 years was a statistically significant poor prognostic factor for complete remission (CR), overall survival (OS), remission duration, and relapse-free survival (RFS). Population-based studies have reported 3- and 5-year survival rates of only $9 \%$ to $10 \%$ and $3 \%$ to $8 \%$, respectively, in patients over age 60 , compared with 5-year survival rates of up to $50 \%$ for younger patients ${ }^{[6]}$.

Poorer outcome has traditionally been considered to be the result of less intensive therapy in this population, concurrent comorbidities, a higher likelihood of underlying hematopoietic disorders, and biologically poor risk disease.

Moreover, because of the perception that older adults are less likely to do well with standard therapy, clinicians are less likely to treat these patients aggressively or refer them to centers that do so. As such, lower levels of aggressive treatment may compound underlying prognostic differences associated with patient factors and disease.

\section{Pretreatment evaluation}

\subsection{General}

The assessment of an older adult with AML includes those studies used for the pretreatment evaluation of younger adults with AML in addition to more specific investigations of physical functioning, nutrition, and comorbid conditions. Testing specific for older adults is presented in the following sections.

\subsection{Physical functioning}

The patient's performance status and ability to perform activities of daily living are measures of physical function that can help to predict the ability to withstand rigorous chemotherapy regimens. 


\subsection{Performance status}

Several studies have supported the use of the Eastern Cooperative Oncology Group (ECOG) and Karnofsky performance status as measures of physical functioning and prognosis in patients with AML.

A retrospective study of data from five Southwestern Oncology Group (SWOG) trials that included 968 patients with AML found that the mortality rate within 30 days of initiation of induction therapy is dependent upon both the patient's age and ECOG performance status (PS) at diagnosis ${ }^{[7]}$.

Thirty-day mortality rates were 2 to 3 percent for patients under the age of 55 years regardless of the PS. For patients over age 55 years, mortality rates ranged from 5 to 18 percent for patients with a PS of zero or 1 . Patients 55 to 65 years old with a PS of 2 had a similar mortality rate 18 percent. Patients over age 55 years with a PS of 3 and those over age 65 with a PS of 2 or 3 had much higher mortality rates that ranged from 29 to 82 percent. The proportion of patients with poorer performance status increased with age.

\subsection{Comorbid conditions}

Comorbid conditions are poor prognostic factors in older patients with AML ${ }^{[8]}$. Patients with age-related chronic cardiac, pulmonary, hepatic or renal disorders or diabetes suffer greater acute toxicity from chemotherapy.

Older patients may also have decreased bone marrow regenerative capacity, even after successful leukemia cytoreduction. Inability to tolerate long periods of pancytopenia and malnutrition or the nephrotoxicity of drugs such as aminoglycosides or amphotericin remains a major barrier to successful treatment.

\subsection{Family discussions}

A discussion with the patient and family members should include a review of the following Prognostic information allowing them to make informed decisions on the type of treatment to be pursued ${ }^{[9]}$. Regardless of treatment choice, patients and their family members often report not being offered alternative treatment options and tend to overestimate the chance of cure ${ }^{[10]}$. Written consent forms required for clinical trials may serve an educational role, even for those who do not desire to enter into a formal study.

- Who has durable power of attorney for health issues if the patient becomes unable to make decisions?

- Does the patient have an updated will?

- Do other members of the family know where this information is kept?

- Will the family have access to adequate funds while the patient is hospitalized?

A discussion concerning "code" status and the possibility that the patient might need to be transferred to an intensive care unit, with its attendant morbidity and mortality ${ }^{[11]}$. This should include issues related to "do not resuscitate" and "do not intubate" orders, such that the patient and family can make properly informed decisions on these matters. The effect on the patient's employment. Most patients will not be able to return to even part-time work until the completion of induction and consolidation chemotherapy.

\section{Overview of treatment}

\subsection{Goals}

The goal of remission induction chemotherapy is the rapid restoration of normal bone marrow function and attainment of complete remission. 
Induction therapy aims to reduce the total body leukemia cell population from approximately $10^{12}$ to below the cytologically detectable level of about $10^{9}$ cells. It is generally assumed, however, that a substantial burden of leukemia cells persists undetected (i.e. minimal residual disease), leading to relapse within a few weeks or months if no further therapy were administered.

Postinduction or "remission consolidation" therapy usually comprises one or more courses of chemotherapy or hematopoietic cell transplantation (HCT). It is designed to eradicate residual leukemia, allowing the possibility of cure. Rates of relapse and death are quite low after three to four years in remission, and most such patients are long-term disease-free survivors ${ }^{[12]}$.

\subsection{Decision to treat}

After the diagnosis of AML has been established, the physician and staff must present the goals of therapy, as well as the side effects of treatment, to the patient and family. For almost all patients, this discussion can emphasize the potential benefits of intensive treatment with regard to both the short and long term outcome. Remission induction, even if short-lived, is an appropriate goal for most patients with AML.

Patients who achieve a remission have an improved quality of life compared with those patients who receive palliative therapy likely because they require fewer hospitalizations, transfusions, and antibiotics ${ }^{[13]}$. Attainment of CR following intensive chemotherapy is required in order to assure meaningful prolongation of life.

Occasionally, intensive treatment with the intent to achieve CR may be less advisable because of advanced patient age, debility, presence of significant co-existing medical problems, and/or prior chemotherapy ${ }^{[14]}$. Patients unlikely to survive treatment can be identified by their poor performance status using the Karnofsky or ECOG (Zubrod) performance. In addition, there are a few patients with "acute leukemia" by the usual quantitative criteria of $>20$ percent bone marrow blast cells whose disease has a much more smoldering course. These patients suffer from bone marrow failure and pancytopenia more than hyperleukocytosis. Their survival may be equally long and their quality of life better, using transfusion support and antibiotics rather than intensive chemotherapy. This may be particularly true for the "hypoplastic/hypocellular" variant of AML.

Supportive care may also be beneficial in acutely infected patients with advanced myelodysplastic syndromes. Occasionally, the clinical picture mimics AML, but resolves following treatment of the infection. For otherwise healthy (ECOG performance status of two or less and few comorbidities) older adults with newly diagnosed AML, we suggest remission induction treatment, ideally on a clinical trial. For older patients with indolent AML, severe comorbidity, or high risk disease, we suggest the use of supportive care rather than standard induction chemotherapy.

It is frequently appropriate and necessary to repeat this discussion and counseling later during the patient's course, as a diagnosis of acute leukemia often leaves the patient and family unable to cope with the longer term consequences of this diagnosis until the patient has successfully passed through the initial weeks of chemotherapy and recovery.

\subsection{I mportance of prognostic molecular markers}

In addition to some well-defined prognostic markers, such as WBC counts, cytogenetics and comorbid illness at diagnosis, mounting evidences show molecular alterations play an important role in AML leukemogenesis. Recently, incorporation of molecular markers was proved to predict clinical outcome of AML patients. Recent studies have identified novel recurrent somatic mutations in patients with AML. These include mutations in TET2 ${ }^{[15,16]}$, ASXL1 ${ }^{[17]}$, IDH1 or IDH2 ${ }^{[18-20]}, D^{D N M T 3 A}{ }^{[21]}$ and PHF6 ${ }^{[22]}$. Retrospective analyses suggest that a subset of these mutations may have prognostic significance in AML ${ }^{[23]}$. Recent research shows that that DNMT3A and NPM1 mutations and MLL translocations predicted an improved outcome with high-dose induction chemotherapy in patients with AML. These 
findings suggest that mutational profiling could potentially be used for risk stratification and to inform prognostic and therapeutic decisions regarding patients with AML ${ }^{[24,25]}$. Use of molecule-targeted therapies may prove to be less toxic and/or more efficacious in selected patients ${ }^{[22]}$.

AML is most common in the elderly, and most elderly are thought to be unfit for intensive treatment because of the risk of fatal toxicity. The Swedish Acute Leukemia Registry covers 98\% of all patients with AML (nonacute promyelocytic leukemia) diagnosed in 1997 to 2005 ( $n=2767$ ), with a median follow-up of 5 years, and reports eligibility for intensive therapy, PS, complete remission rates, and survival. Outcomes were strongly age and PS dependent. Early death rates were always lower with intensive therapy than with palliation only. Long-term survivors were found among elderly given intensive treatment despite poor initial PS. Total survival of elderly AML patients was better in the geographic regions where most of them were given standard intensive therapy. This analysis provides unique real world data from a large, complete, and unselected AML population; both treated and untreated, and give background to treatment decisions for the elderly. Standard intensive treatment improves early death rates and long-term survival compared with palliation. Most AML patients up to 80 years of age should be considered fit for intensive therapy, and new therapies must be compared with standard induction ${ }^{[13]}$.

\section{Induction}

The best treatment strategy for older patients with AML remains controversial. Among the treatment options that have been evaluated are various forms of intensive or less-intensive chemotherapy, the administration of colony-stimulating factors to enhance neutrophil recovery, supportive therapy, low-dose cytarabine, high- or intermediate-dose cytarabine-based consolidation therapy, prolonged consolidation therapy, and maintenance treatment with interferon. Most of these studies have been disappointing.

\subsection{I ntensive chemotherapy}

The best induction chemotherapy for older patients with AML remains to be identified. Intensive chemotherapy may be appropriate for selected patients with low or intermediate risk disease in whom the CR rate can be as high as 70 to 80 percent. With this approach, median survival is approximately eight months, but 9 to 12 percent of patients will be alive at five years. Although pilot studies have used more intensive initial chemotherapy, a reasonable standard regimen for many older patients who are medically fit is seven days of continuous infusion cytarabine (ara-C, $100 \mathrm{mg} / \mathrm{m}^{2}$ per day) plus three days of daunorubicin (60 or $90 \mathrm{mg} / \mathrm{m}^{2}$ per day).

Randomized trials have investigated various modifications of cytarabine plus an anthracycline for the treatment of older adults with AML.

In general, the choice of anthracycline (e.g., daunorubicin, mitoxantrone, or idarubicin) does not appear to affect overall outcome. However, higher doses of anthracyclines may result in superior rates of CR without an apparent increase in toxicity.

For most of older adults with favorable or intermediate risk AML and an ECOG performance status of two or less and few comorbidities, we suggest remission induction treatment with a combination of an anthracycline such as daunorubicin for three days and "standard" dose cytarabine for seven days rather than other chemotherapy regimens or supportive care alone. When induction treatment is chosen, it should be applied at sufficient dose intensity to provide the best chance of success.

\subsection{Use of growth factors}

Several groups have evaluated the effects of colony-stimulating factors (e.g., GM-CSF, G-CSF, and glycosylated G-CSF) as an adjunct to intensive chemotherapy with largely disappointing results. The rationale for this approach is that older 
patients are particularly susceptible to infection and experience a higher infectious mortality rate during episodes of neutropenia. Shortening the duration of neutropenia might have a beneficial effect and improve the rate of complete remission ${ }^{[26]}$.

\subsection{What treatment options are available for patients who are not candidates for intensive induction therapy?}

For those patients who are not considered to be candidates for intensive induction therapy, one would hope to identify agents and regimens that are more effective and less toxic to address the concerns regarding early induction death, inadequate response rate, and high risk of relapse ${ }^{[27,28]}$.

Data available on novel agents comes from a variety of pilot and phase II studies with differing eligibility criteria. When evaluating the outcomes, it is important to also look at the characteristics of patients who were ultimately enrolled reviews available data from some of these studies.

As part of the NCRI AML 14 study, 212 patients who were deemed unfit for intensive treatment options by the local investigator were randomized to receive supportive care alone with hydroxyurea or cytarabine $20 \mathrm{mg}$ twice daily by subcutaneous injection for 10 days every 4 to 6 weeks. Outcome was improved for the low-dose (LD) cytarabine arm when compared with supportive care with hydroxyurea alone. CR was $18 \%$ versus $1 \%$, and median survival was 575 days for those who achieved CR, compared with 66 days in nonresponders. DFS for responders was 8 months. Survival benefit was seen in all age groups, even those over age 75. As none of the patients with adverse cytogenetics achieved a CR, no survival benefit was, however, seen in that group. The early death rate was $39 \%$ at 8 weeks ${ }^{[29]}$. Based on this study, LD cytarabine became the standard of care for the treatment of patients felt to be unfit for intensive chemotherapy, although one could argue that it should not be given to those with poor risk cytogenetics.

In a study of azacitidine in AML with $20 \%$ to $30 \%$ blasts, patients who were deemed unfit for standard induction chemotherapy were randomized against either supportive care or LD cytarabine ${ }^{[30]}$. OS survival was superior in the azacitidine arm. There was a statistically significant difference seen in OS for patients with poor risk cytogenetics in favor of azacitidine, compared with conventional care regimens (12.3 vs. 5.3 months, respectively, with 2-year OS of $38 \%$ vs. $0 \%$ ). Gemtuzumab ozogamicin (GO) has been the subject of a recent study by the EORTC and GIMEMA leukemia groups (AML 19) ${ }^{[31]}$. In this randomized multicenter study, 84 patients were randomizedto receive one of two schedules of GO at attenuated doses or best supportive care. The proportion of patients either achieving a response or maintaining stable disease was greater in patients who receive GO at a dose of $6 \mathrm{mg} / \mathrm{m}^{2}$ on day 1 and $3 \mathrm{mg} / \mathrm{m}^{2}$ on day 8 , when compared with a schedule of GO $3 \mathrm{mg} / \mathrm{m}^{2}$ on days 1, 3, and 5 (63\% vs. 38\%, respectively).

Results of the comparison with patients who were randomized to standard care are not yet available, and a phase III trial is ongoing. Clofarabine has been studied as an agent in elderly patients with AML. In two consecutive European studies of 106 untreated older patients with AML who were considered unfit for chemotherapy, participants were given four to six 5-day courses of clofarabine ${ }^{[32]}$. In the UWCM (University of Wales College of Medicine) -001 study, patients who were either over age 70 (68\%) or over age 60, with a PS of 2 or cardiac comorbidity, were treated with clofarabine for 5 days every 28 days for 2 to 4 courses. In the BIOV-121 study, patients were treated for 5 days every 4 to 6 weeks for up to six courses. All patients were age 65 and deemed unfit for chemotherapy.

Overall, $36 \%$ of patients had a PS 2, 30\% had adverse risk cytogenetics, $46 \%$ had Wheatley poor risk disease, and $65 \%$ were age 70 . The ORR was $48 \%$, and the median OS was 19 weeks for all and 45 weeks for those who attained a $\mathrm{CR} /$ completeremission with incomplete blood count recovery (CRi). Responses were seen in patients with adverse cytogenetics (44\% ORR), patients with secondary AML (31\%), and patients age 70 (49\%). The death rate within 30 days was $18 \%{ }^{[33]}$. 
A novel agent, laromustine (VNP40101M), a sulfonylhydrazine alkylatingagent, has been studied in 85 patients with poor risk AML age 60 years. 51 Patients received one to two cycles of laromustine at a doseof $600 \mathrm{mg} / \mathrm{m}^{2}$, followed by one cycle of cytarabine. Seventy-eightpercent of patients were age 70, 47\% had an adverse karytype, 41\%had a PS of 2, 77\% had pulmonary disease, $73 \%$ had cardiac disease, and 3\% had hepatic disease.

All patients with unfavorable karyotype or ECOG PS had at least one other risk factor at the time of enrollment. Seventy-five percent of patients had 3 risk factors. The ORR was32\% and was similar in patients over age 70 (32\%), with a PS of 2 (32\%), with baseline pulmonary or cardiac dysfunction (27\%-34\%). There was a14\% 30-day mortality. OS was 3.2 months (12.4 months for those with CR/CRp), and 1-year survival was 21\% (52\% for those with CR/CRp). These phase II studies are encouraging, in that responses are seen in all poor risk categories, and early death rates are acceptable. Randomized trials are needed.

\section{Post remission therapy}

While a substantial percentage of older adults will attain a CR with induction chemotherapy, virtually all of these patients will relapse within a median of four to eight months unless given additional cytotoxic therapy. Even with post-remission therapy, relapses are common. Only about 10 percent of older adults, and generally only those with favorable or intermediate risk disease, attain long term survival after the administration of post-remission therapy ${ }^{[34]}$. Post-remission therapy aims to destroy leukemia cells that survived induction chemotherapy but are undetectable by conventional studies.

There are two generally accepted options for post-remission therapy: consolidation chemotherapy and allogeneic HCT. Consolidation chemotherapy is less intensive and has a lower early mortality rate, but allogeneic HCT provides a graft-versus-tumor effect that decreases relapse rates. In younger patients, consolidation chemotherapy is usually given to patients with favorable risk disease while HCT is used for patients with unfavorable risk disease. The optimal treatment for intermediate risk disease is unknown. Evidence regarding the therapeutic benefit of any consolidation therapy in older patients with AML is limited and its value has remained uncertain. Newly discovered genetic markers are helping to refine the risk stratification. A detailed description of these options in younger adults is presented separately.

Post-remission therapy in older adults is complicated by high rates of treatment related toxicity. Older adults are generally not candidates for a fully myeloablative allogeneic HCT, but a subset may be able to undergo nonmyeloablative HCT after reduced intensity conditioning regimens.

A choice among these strategies is generally made based upon the risk stratification of the patient's tumor and the patient's performance status and comorbidities that might affect tolerance of intensive therapy. A phase III trial demonstrated that post-remission therapy with single agent gemtuzumab ozogamicin did not improve clinical outcomes (probability of relapse, overall survival, or disease free survival), but added toxicities ${ }^{[35]}$.

\subsection{Consolidation chemotherapy}

High dose cytarabine (HiDAC) is the standard consolidation chemotherapy for younger adults with AML of a favorable risk, but is associated with unacceptably high rates of severe toxicity and early death in older adults that counteract any improvement in efficacy over standard dose cytarabine.

Instead, consolidation therapy with two cycles of daunorubicin (30 to $45 \mathrm{mg} / \mathrm{m}^{2}$ for two days) and cytarabine (Ara-C, 100 $\mathrm{mg} / \mathrm{m}^{2}$ per day for five days) for older adults is preferred. The use of consolidation chemotherapy in younger adults is presented separately ${ }^{[36]}$. 


\subsection{Nonmyeloablative transplantation}

Allogeneic hematopoietic cell transplantation (Allo-HCT) is the preferred treatment for younger adults with unfavorable risk AML because of its graft-versus-leukemia effect. However, Allo-HCT is associated with a very high treatment-related mortality rate in older patients that precludes its general use. Instead, various reduced intensity or nonmyeloablative ${ }^{\text {[37] }}$ Allo-HCT regimens have been employed in fit older adults. However, the comparable efficacy of this approach remains to be proven and a randomized, multinational trial by the European Group for Blood and Marrow Transplantation evaluating AlloSCT versus conventional consolidation therapy in elderly patients is currently accruing patients.

The development of less toxic and better tolerated nonmyeloablative regimens capable of inducing a state of mixed chimerism may allow Allo-HCT to be performed in patients with AML and advanced age or co-morbidity, with the hope that such regimens would result in lower rates of treatment-related mortality without sacrificing relapse-free and overall survival, and with a reasonable balance between GVHD and the graft-versus-tumor effect. Additional experience with this approach is awaited.

\section{Supportive care}

For older patients with indolent AML, severe comorbidity, or high risk disease, we suggest the use of supportive care rather than induction chemotherapy. Supportive care can include the use of red blood cell and platelet transfusions, antibiotics, and control of leukocytosis with agents such as low-dose cytarabine or hydroxyurea.

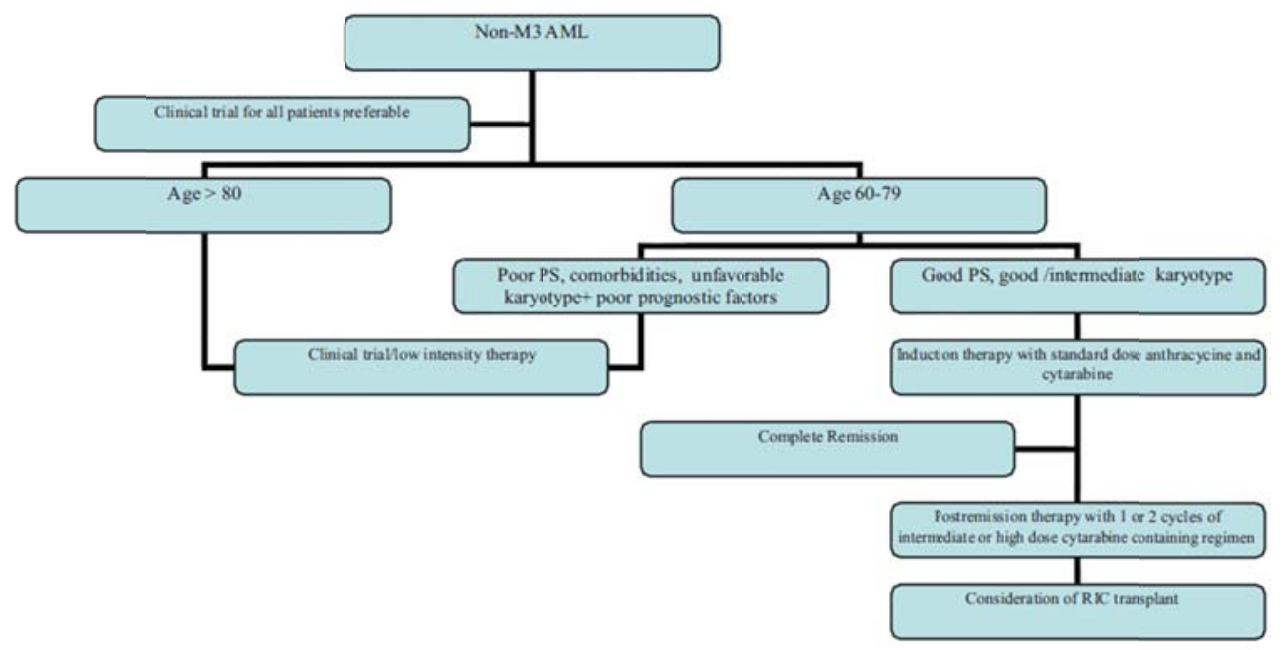

Figure 1. Outlines approach to the elderly patient with AML

\subsection{Low-dose cytarabine}

While not curative, many committees, including the British Committee for Standards in Hematology, consider low-dose cytarabine to be the standard against which other palliative treatments for AML in the older patient should be evaluated. A number of trials have investigated the use of low-dose cytarabine in older subjects with AML, both for induction and later for maintenance of remission ${ }^{[38]}$.

\subsection{Other supportive measures}

Other measures of supportive care include the use of leukocyte-depleted, irradiated red blood cell and platelet transfusions as needed and the use of antibiotics to treat infections. As described above, patients treated with supportive care alone spend a similar amount of time in the hospital compared with those who receive intensive chemotherapy. 


\subsection{Approach to the elderly patient with AML}

AML is a disease of the elderly, with the majority of patients over age 60. With our population ages, that percentage will only increase. Unfortunately, the standard regimens that are successful in treating younger patients with AML are not as beneficial in the majority of older patients with the disease. Figure 1 outlines my approach to the elderly patient with AML. Understanding of the disease biology, as well as the prognostic factors associated with the host, allows us to better determine which patients are likely to benefit from standard therapy and which require alternative approaches. Objective scoring systems are being developed that allow us to define patients unfit for intensive chemotherapy on the basis of increased risk of induction death, low response rate, and/or low long-term DFS. Optimal induction and postremission therapy for patients appropriate for intensive therapy have yet to be defined, again, because results are not satisfactory with our current regimens, even in those patients who do not have definable poor prognostic factors. When compared with young patients with similar disease-related features, outcomes are inferior. For patients who are not candidates for intensive therapy because of comorbid conditions, low-intensity therapies appear to be superior to palliative care alone. Whenever possible, patients should be enrolled in clinical trials that will allow us to address these issues.

\section{References}

[1] Schiffer, CA. "I am older, not elderly," said the patient with acute myeloid leukemia. J Clin Oncol. 2010; 28: 521. PMid:20026796 http://dx.doi.org/10.1200/JCO.2009.25.8616

[2] Surveillance Epidemiology and End Results (SEER) Program. Limited use-data (1973-2004). National Cancer Institute D, Surveillance Research Program, Cancer Statistics Branch [Internet]. Available from: http:// www.seer.cancer.gov. Accessed April 2007.

[3] Juliusson G, Antunovic P, Derolf A, et al. Age and acute myeloid leukemia: real world data on decision to treat aml. 2009; 113: 4179-4187.

[4] Pulte D, Gondos A, Brenner H, Pulte D, Gondos A, Brenner H. Improvements in survival of adults diagnosed with acute myeloblastic leukemia in the early 21st century. Haematologica. 2008; 93: 594-600. PMid:18322250 http://dx.doi.org/10.3324/haematol.12304

[5] Buchner T, Berdel WE, Haferlach C, et al. Age-related risk profile and chemotherapy dose response in acute myeloid leukemia: a study by the German Acute Myeloid Leukemia Cooperative Group. J Clin Oncol. 2009; 27: 61-69. PMid:19047294 http://dx.doi.org/10.1200/JCO.2007.15.4245

[6] Lerch E, Espeli V, Zucca E, et al. Prognosis of acute myeloid leukemia in the general population: data from southern Switzerland.

[7] Appelbaum, FR, Gundacker, H, Head, DR, et al. Age and acute myeloid leukemia. Blood. 2006; 107: 348. PMid:16455952 http://dx.doi.org/10.1182/blood-2005-09-3724

[8] Wheatley, K, Brookes, CL, Howman, AJ, et al. Prognostic factor analysis of the survival of elderly patients with AML in the MRC AML11 and LRF AML14 trials. Br J Haematol. 2009; 145: 598. PMid:19344426 http://dx.doi.org/10.1111/j.1365-2141.2009.07663.x

[9] Estey, E. Acute myeloid leukemia and myelodysplastic syndromes in older patients. J Clin Oncol. 2007; 25: 1908. PMid:17488990 http://dx.doi.org/10.1200/JCO.2006.10.2731

[10] Sekeres, MA, Stone, RM, Zahrieh, D, et al. Decision-making and quality of life in older adults with acute myeloid leukemia or advanced myelodysplastic syndrome. Leukemia. 2004; 18: 80. PMid:14762444 http://dx.doi.org/10.1038/sj.leu.2403289

[11] Rabbat, A, Chaoui, D, Montani, D, et al. Prognosis of patients with acute myeloid leukaemia admitted to intensive care. Br J Haematol. 2005; 129: 350. PMid:15842658 http://dx.doi.org/10.1111/j.1365-2141.2005.05459.x

[12] Schiffer, CA, Dodge, R, Larson, RA. Long-term follow-up of Cancer and Leukemia Group B studies in acute myeloid leukemia. Cancer. 1997; 80: 2210. http://dx.doi.org/10.1002/(SICI)1097-0142(19971201)80:11+<2210::AID-CNCR8>3.0.CO;2-L

[13] Juliusson, G, Antunovic, P, Derolf, A, et al. Age and acute myeloid leukemia: real world data on decision to treat and outcomes from the Swedish Acute Leukemia Registry. Blood. 2009; 113: 4179. PMid:19008455 http://dx.doi.org/10.1182/blood-2008-07-172007

[14] Appelbaum, FR, Gundacker, H, Head, DR, et al. Age and acute myeloid leukemia. Blood. 2006; 107: 3481 PMid:16455952 http://dx.doi.org/10.1182/blood-2005-09-3724

[15] Delhommeau F, Dupont S, Della Valle V, et al. Mutation in TET2 in myeloid cancers. N Engl J Med. 2009; 360: $2289-301$. PMid:19474426 http://dx.doi.org/10.1056/NEJMoa0810069 
[16] Abdel-Wahab O, Mullally A, Hedvat C, et al. Genetic characterization of TET1, TET2, and TET3 alterations in myeloid malignancies. Blood. 2009; 114: 144-7. PMid:19420352 http://dx.doi.org/10.1182/blood-2009-03-210039

[17] Metzeler KH, Becker H, Maharry K, et al. ASXL1 mutations identify a highrisk subgroup of older patients with primary cytogenetically normal AML within the ELN Favorable genetic category. Blood. 2011; 118: 6920-9. PMid:22031865 http://dx.doi.org/10.1182/blood-2011-08-368225

[18] Mardis ER, Ding L, Dooling DJ, et al. Recurring mutations found by sequencing an acute myeloid leukemia genome. N Engl J Med. 2009; 361: 1058-66. PMid:19657110 http://dx.doi.org/10.1056/NEJMoa0903840

[19] Ward PS, Patel J, Wise DR, et al. The common feature of leukemia-associated IDH1 and IDH2 mutations is a neomorphic enzyme activity converting alphaketoglutarate to 2-hydroxyglutarate. Cancer Cell. 2010; 17: 225-34. PMid:20171147 http://dx.doi.org/10.1016/j.ccr.2010.01.020

[20] Marcucci G, Maharry K, Wu YZ, et al. IDH1 and IDH2 gene mutations identify novel molecular subsets within de novo cytogenetically normal acute myeloid leukemia: a Cancer and Leukemia Group B study. J Clin Oncol. 2010; 28: $2348-55$. PMid:20368543 http://dx.doi.org/10.1200/JCO.2009.27.3730

[21] Yan XJ, Xu J, Gu ZH, et al. Exome sequencing identifies somatic mutations of DNA methyltransferase gene DNMT3A in acute monocytic leukemia. Nat Genet. 2011; 43: 309-15. PMid:21399634 http://dx.doi.org/10.1038/ng.788

[22] Van Vlierberghe P, Patel J, Abdel-Wahab O, et al. PHF6 mutations in adult acute myeloid leukemia. Leukemia. 2011; $25:$ 130-4. PMid:21030981 http://dx.doi.org/10.1038/leu.2010.247

[23] Ley TJ, Ding L, Walter MJ, et al. DNMT3Amutations in acute myeloid leukemia.N Engl J Med. 2010; 363: $2424-33$. PMid:21067377 http://dx.doi.org/10.1056/NEJMoa1005143

[24] Patel et al, NEJM, 2012, ELN guideline, Blood, 2010, etc.

[25] Patel et al, NEJM, 2012, ELN guideline, Blood, 2010, etc.

[26] Goldstone, AH, Burnett, AK, Wheatley, K, et al. Attempts to improve treatment outcomes in acute myeloid leukemia (AML) in older patients: the results of the United Kingdom Medical Research Council AML11 trial. Blood. 2001; 98: 1302. PMid:11520775 http://dx.doi.org/10.1182/blood.V98.5.1302

[27] Burnett AK, Milligan D, Goldstone A, et al. The impact of dose escalation and resistance modulation in older patients with acute myeloid leukaemia and high risk myelodysplastic syndrome: the results of the LRF AML 14 trial. Br J Haematol. 2009; 145: 318-332. PMid:19291085 http://dx.doi.org/10.1111/j.1365-2141.2009.07604.x

[28] Burnett AK, Milligan D, Prentice AG, et al. A comparison of low-dose cytarabine and hydroxyurea with or without all-trans retinoic acid for acute myeloid leukemia and high-risk myelodysplastic syndrome in patients not considered fit for intensive treatment. Cancer. 2007; 109: 1114-1124. PMid:17315155 http://dx.doi.org/10.1002/cncr.22496

[29] Wheatley K, Brookes CL, Howman AJ, et al. Prognostic factor analysis of the survival of elderly patients with AML in the MRC AML11 and LRF AML14 trials. Br J Haematol. 2009; 145: 598-605. PMid:19344426 http://dx.doi.org/10.1111/j.1365-2141.2009.07663.x

[30] Fenaux P, Mufti GJ, Hellstrom-Lindberg E, et al. Azacitidine prolongs overall survival compared with conventional care regimens in elderly patients with low bone marrow blast count acute myeloid leukemia. J Clin Oncol. 2010; 28: 562-569. PMid:20026804 http://dx.doi.org/10.1200/JCO.2009.23.8329

[31] Amadori S, Suciu S, Selleslag D, et al. Randomized trial of two schedules of low-dose gemtuzumab ozogamicin as induction monotherapy for newly diagnosed acute myeloid leukaemia in older patients not considered candidates for intensive chemotherapy. (A phase II study of the EORTC and GIMEMEA leukaemia groups (AML-19).) Br J Haematol. 2010; 149: 376-382. PMid:20230405 http://dx.doi.org/10.1111/j.1365-2141.2010.08095.x

[32] Kantarjian HM, Erba HP, Claxton D, et al. Phase II study of clofarabine monotherapy in previously untreated older adults with acute myeloid leukemia and unfavorable prognostic factors. J Clin Oncol. 2010; 28: 549-555. PMid:20026805 http://dx.doi.org/10.1200/JCO.2009.23.3130

[33] Russell NH, Hills RK, Hunter AE, et al. Low dose ara-C versus low dose ara-C and arsenic trioxide: the UK NCRI AML16“pick a winner” comparison [abstract 486]. Blood. 2009; 114.

[34] Cassileth, PA, Harrington, DP, Hines, JD, et al. Maintenance chemotherapy prolongs remission duration in adult acute nonlymphocytic leukemia. J Clin Oncol. 1988; 6: 583. PMid:3282032

[35] Löwenberg, B, Beck, J, Graux, C, et al. Gemtuzumab ozogamicin as postremission treatment in AML at 60 years of age or more: results of a multicenter phase 3 study. Blood. 2010; 115: 2586. PMid:20103782 http://dx.doi.org/10.1182/blood-2009-10-246470

[36] Gardin, C, Turlure, P, Fagot, T, et al. Postremission treatment of elderly patients with acute myeloid leukemia in first complete remission after intensive induction chemotherapy: results of the multicenter randomized Acute Leukemia French Association (ALFA) 9803 trial. Blood. 2007; 109: 5129. PMid:17341661 http://dx.doi.org/10.1182/blood-2007-02-069666 
[37] Wallen, H, Gooley, TA, Deeg, HJ, et al. Ablative allogeneic hematopoietic cell transplantation in adults 60 years of age and older. J Clin Oncol. 2005; 23: 3439. PMid:15824415 http://dx.doi.org/10.1200/JCO.2005.05.694

[38] Kantarjian, H, O'brien, S, Cortes, J, et al. Results of intensive chemotherapy in 998 patients age 65 years or older with acute myeloid leukemia or high-risk myelodysplastic syndrome: predictive prognostic models for outcome. Cancer. 2006; 106 : 1090. PMid:16435386 http://dx.doi.org/10.1002/cncr.21723 